\title{
ACUTE PULMONARY OEDEMA AT HIGH ALTITUDE
}

\author{
Major K. HEDGES, M.Sc., M.B., Ch.B., D.T.M.\&H., D.I.H., R.A.M.C. \\ Headquarters, 3rd Division, Bulford Camp
}

\begin{abstract}
SUMMARY : An incident of acute pulmonary oedema occurring in a Junior Guardsman at an altitude of 13,000 feet is described.

A review of the present knowledge of this condition is presented together with current views upon the early recognition and management of a case presenting on the mountainside and the rationale of prevention.
\end{abstract}

\section{Introduction}

"In the next few hours (his) breathing became progressively more congested and laboured. He sounded as though he were literally drowning in his own fluid, with an almost continuous bubbling sound as if breathing through liquid. A couple of hours after his death ... I noticed that a white froth ... had appeared well up out of his mouth."

This vivid description by a non-medical correspondent prefaced the first documented report of a case of acute pulmonary oedema published in English (Houston 1960).

The only statistical record of pulmonary oedema at altitude in the British Armed Services occurred on the 1970 Annapurna Expedition. This officer survived only to be killed the following year in Northern Ireland. His case was distinctive in being a relapse of an earlier episode which had developed whilst training in Switzerland in 1969 and is unusual in being one of the few documented cases reported in Europe (Milne 1973). There has, for example, been no known case on the Matterhorn-14,679 feet (Cerretelli 1972), although it is considered possible that some cases of pulmonary congestion recorded by Mosso (1898) and by Durig and Zuntz (1904), to in fact have been descriptions of acute pulmonary oedema occurring at altitude in the European Alps.

Several incidents of acute pulmonary oedema have however recently occurred amongst British servicemen whilst engaged upon energetic and demanding pursuits on Mount Kenya (Snyder 1973). These include a Marine in October 1971, and a member of a Royal Air Force Mountain Rescue Team in March 1973, both of whom had arrived on the mountain within days of leaving sea-level.

A paratrooper who had ascended to 15,700 feet on the second day after leaving sea-level died in respiratory failure whilst being carried off the mountain (Woodley 1972). The apparently high number of cases of pulmonary oedema on this mountain is almost certainly a function of its accessibility vis-a-vis other high mountains of the world.

\section{An account of acute pulmonary oedema on Mount Kenya}

A Junior Guardsman, M. R., aged 16, arrived at Base Camp (8,000 feet) towards the end of the millet harvest season (January to March), a period generally reckoned to be a good time for travel on the mountain (Mitchell 1971). Although the Anopheline mosquito is not found at this height, M.R. was taking malarial prophylaxis, Proguanil Hydrochloride tablets BP $0.1 \mathrm{~g}$ daily, and spent some three weeks in the Base Camp 
area as part of an advance party for a larger project. Table 1 shows the average weather profile during this period at Nanyuki $0^{\circ} 01^{\circ} \mathrm{N}, 37^{\circ} 04^{\circ} \mathrm{E}$, March 1973, and it will be seen that this represents little, if any, heat stress. During his stay M.R. had become welltanned by regular and graduated exposure to sunlight and was in excellent physical shape.

Table I

Average weather profile at Nanyuki, March 1973

\begin{tabular}{|c|c|c|c|}
\hline \multicolumn{2}{|c|}{ Average daily temperature } & \multicolumn{2}{|c|}{ Average relative humidity } \\
\hline Maximum & Minimum & 0800 hours & 1400 hours \\
\hline 77 degrees & 49 degrees & 66 degrees & 33 degrees \\
\hline
\end{tabular}

M.R. and his group began their ascent on Mount Kenya by driving to the road head at 9,600 feet. From there, the march began and at night fall the party reached its highest point at 13,000 feet. M.R. felt perfectly well at this time, although several of his companions were complaining of mild frontal headache. Water was not plentiful, only 4 pints being consumed during the thirty-six hour trek.

During the evening, M.R. began to feel listless and weak and remembers having some difficulty in understanding when people spoke to him. He had no appetite and was noted to look pale and have bloodshot eyes. Although not noticed at the time, M.R. subsequently admitted on direct questioning that his breathing had become irregular, he had noticed himself sighing. Perhaps most significant, and a fact which he had not realised to be so, was that he could hear bubbling noises in his chest. He did not sleep well during the night stop and began the next day with a dry cough. During the descent he felt greatly fatigued and vomited once before returning to the Base Camp at 8,000 feet, some 36 hours after having first left it. For the next four days he felt off colour and was at times disoriented. He was therefore taken to Nanyuki Cottage Hospital, where he was found on admission to be cyanosed and to have rales in the right lower lobe. He was apyrexial and no other abnormal signs were elicited. A diagnosis of Pulmonary Oedema was made and the patient responded to Frusemide (Lasix) $40 \mathrm{mg}$ tablets, two every 6 hours with a steady clinical improvement and moderate diuresis, being discharged two days later.

Figure 1 shows British Troops climbing at 13,500 feet towards the snow-covered peaks of Mount Kenya. The unique giant vegetation (Senecio brassica, the "Cabbage Groundsel ") is found only within the zone, 10,000 to 14,000 feet.

\section{Discussion}

Pulmonary oedema is an abnormal accumulation of liquid in the extra-vascular tissues and spaces of the lung (Robin et al 1973). There are many causes for this disorder amongst which are listed left ventricular failure, mitral stenosis and non-cardiac conditions such as pulmonary embolism, parenchymal lung disease, narcotic overdose and most recently, exposure to high altitude (Brit. med. J. 1973).

Mosso (1898) had first described the phenomenon of a changed breathing rhythm at altitude, known as Cheyne-Stokes Breathing, which in other circumstances " A 


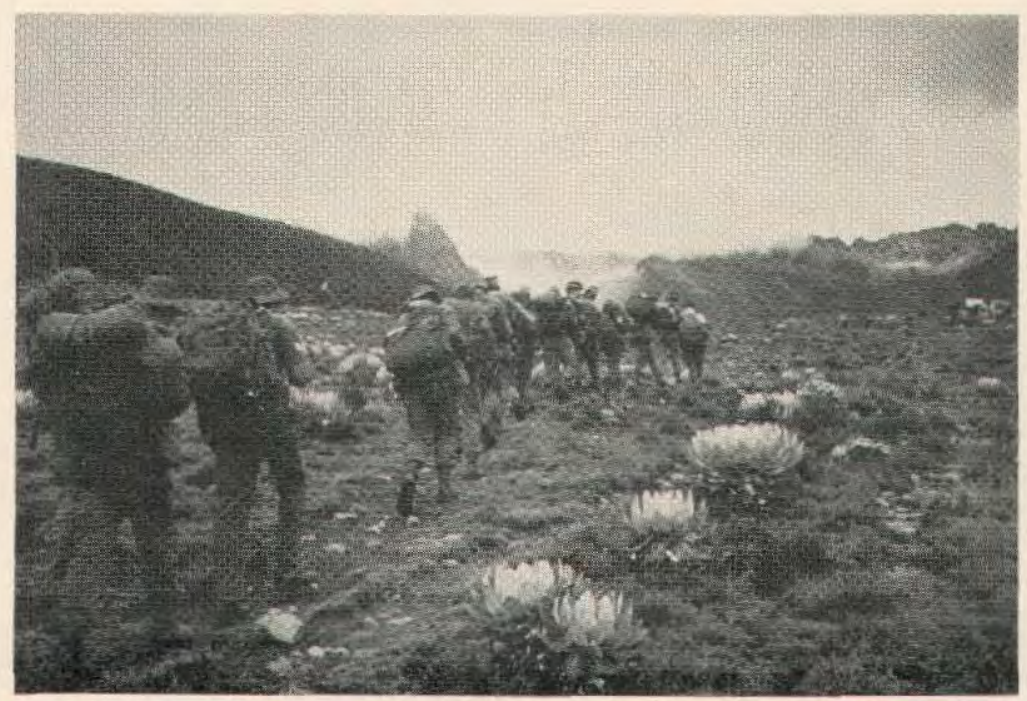

Fig. 1. British troops climbing at 13,500 feet.

physician would say ... that they were of a dying person." This is particularly noticeable at sleep and is often experienced by non-acclimatised individuals who may wake up due to discomfort and distress associated with breathing (Folk 1966).

Monge's pioneer work in circulatory dynamics (1928) observed that the physiological consequence of exposure to altitude in some subjects resulted tragically when the victim "drowns in his own blood."

Horrobin (1972) has speculated that it may be significant that 9,000 feet below which altitude-induced pulmonary oedema is very rare, is the altitude at which hypoxia begins to dominate the control of ventilation in the presence of a reduced arterial $\mathrm{P}_{\mathrm{CO} 2}$. This in turn triggers mechanisms which tend to lead to a shift of circulating blood to the pulmonary capillary bed.

Singh's report (1969) of 1,925 physically fit men who were incapacitated following their arrival at altitudes above 11,000 feet, is at present the largest series to be published. He considers that Acute Mountain Sickness and High Altitude Pulmonary Oedema are clinical variants of the same disorder and found that a patient may suffer from either one or both illnesses. Concurrently with the development of pulmonary congestion, there was an almost invariable antidiuresis (physiological retention of water) - therapy against which prevents as well as relieves the illness.

Hultgren (1961) in a study in the Peruvian Andes, raised the possibility that people who re-entered an altitude to which they were previously acclimatised were predisposed to pulmonary oedema. This unexpected observation is not, however, confirmed by Singh (1969) and it seems probable that there is no statistically significant relationship.

The mechanism by which pulmonary oedema occurs in some people at moderate and high altitudes is the subject of much complex debate and an increasing volume of field research. 
There are many uncertainties concerning the net effect of forces which produce fluid shifts across the alveolar-pulmonary-capillary compartments of the lungs. These have been surveyed with immense regard for detail in a recent article by Robin et al (1973).

At the present state of knowledge perhaps all that can be said is that an individual who has proved to be susceptible to altitude-induced pulmonary oedema is predisposed to a recurrence if he again returns to altitude. There are, however, many exceptions to this " not only between individuals but in the same individual from time to time." (Houston 1972).

\section{Recognition and treatment}

The onset of pulmonary oedema on the mountainside is confused not only by the presence of the common features of acute mountain sickness, but also by the probable contingency that the vigilance and judgement of other members of the party may also be affected. In which case, the condition may be unrecognised until it is realised that one of the party is in fact seriously ill.

It is known that the early radiological signs of pulmonary oedema precede the clinical presentation of dyspnoea (West 1970). The knowledge of this might appear to be academic half way up a mountain when the whole party is likely to be breathless from exertion at unaccustomed altitude and where reliance in a diagnosis in any case must be placed upon unaided clinical acumen. However, this does corroborate Houston's (1973) preliminary communication on the present Mount Ranier studies where early signs of fluid in the lungs, as determined by ausculation, were found in 22 per cent of those reaching 12,000 feet.

The point to be made is that effective treatment must be based upon early recognition of pulmonary oedema occurring at altitude. The first step then is to be aware of the hazard. Pulmonary oedema may be present with or without other aspects of altitude sickness and has been seen to occur mostly in the individual who reaches 10,000 feet within a few days of leaving sea level. There is a general feeling that an increased susceptibility may exist for the young climber who is in good shape physically and who is able therefore to display considerable vigour during the climb. This view is held most strongly in East Africa where the condition has never been known to occur in a female (Snyder 1973), and not a single case has been reported on Mount Kilimanjaro which is in fact the highest mountain in Africa (Woodley 1973). This is believed to be due to the slow rate of ascent.

It is important to point out, however, that other workers, and particularly the current Ranier studies, have indicated that there is little if any relationship between age, sex, physical condition, smoking and previous altitude experience.

Almost pathognomonic are bubbling noises in the chest which are audible to the patient. This is almost invariably preceded by a dry cough which may subsequently develop into a productive cough with frothy blood-stained sputum. Breathing becomes unduly laboured and may be gasping and irregular. This may be accompanied by a feeling of fullness and tightness in the chest, As the condition worsens, within hours, the patient becomes cyanosed and anxious, with a subjective lowering of expectation of survival. A low grade fever is usually present and the picture is virtually indistinguishable from a pneumonitis of infective origin. 
The condition constitutes a life-threatening situation. The only hope of survival depends upon the concurrent pursuit of three objectives, namely:-

1. The precipitating factor is hypoxia. A rapid descent must be undertaken with the patient on a stretcher. A patient who may not be orthopnoeic may become extremely dyspnoeic on the slightest exertion. If necessary, this journey must be undertaken in darkness. On Mount Kenya, big game will be less hazardous at night if the descent is as noisy as possible. Pure oxygen must be available. It can be administered at an adjusted flow rate depending upon the response of the patient, but in any case has been found to be of decreasing value as the disease progresses (Singh 1965). The administration of oxygen must on no account, therefore, be the reason for a delayed descent. It should be administered during the descent. Descent alone can result in remarkably rapid clinical improvement (Steele 1971).

2. There is an abnormal accumulation of fluid in the lungs. Frusemide produces a marked diuresis with often prompt clinical benefit. It is to be regarded as an essential drug to be administered on the mountainside when pulmonary oedema is suspected. Because of the subsequent dehydration which may result, copious fluids by mouth should be actively encouraged since experience has shown that a dehydrated patient will not always ask for water. Oral fluid will not provoke a relapse of an abnormal accumulation of fluid in the lungs, but it will combat serious dehydration. Tablets (40 mg) should be available on the mountain and two tablets should be administered every six hours (Horrobin 1972). Alternatively, the drug may be administered by intravenous or intramuscular injection $(20 \mathrm{mg}$ in $2 \mathrm{ml})$. This promotes a speedy diuresis within a few minutes and lasting some four hours.

3. Gas exchange is defective. The use of aminophylline and morphine are well established. Aminophylline, which may be given by suppository, increases cardiac output and in addition acts as a broncholdilator (Brit. med. J. 1973). One of the known effects of morphine is to shift blood away from the congested pulmonary circulation and thus improve the ventilation pattern in these patients (Zelis et al 1970). It is said to have an effect which is often dramatic and has been advocated for this purpose by Singh et al, when used in conjunction with other remedies, notably as Bates (1972) dramatically observes, with oxygen and frusemide.

The severe case, who does not recover on reaching low altitude, will deteriorate into progressive respiratory acidosis and coma. It is in such patients that urgent hospitalisation, if possible by helicopter, is imperative, Intermittent possitive-pressure ventilation (I.P.P.V.) has been found to be life-saving in these circumstances. Corretelli (1972) advocates the use of octyl alcohol as a safe anti-foam agent in conjunction with I.P.P.V.

An African, aged 20, belonging to the Teso Tribe turned back at 14,500 feet with very severe headache. During an overnight stop at 13,650 feet he developed a continuous cough and bubbling was heard in his chest. Blood-stained frothy sputum was noticed, After admission to hospital, four hours later, there was rapid and steady clearing of fluid from the lungs during resuscitation with B.O.C. Mark 2 Cyclator automatic lung ventilator, using alcohol as an anti-foam agent. He showed complete recovery twentyeight hours after admission (Fig. 2). 

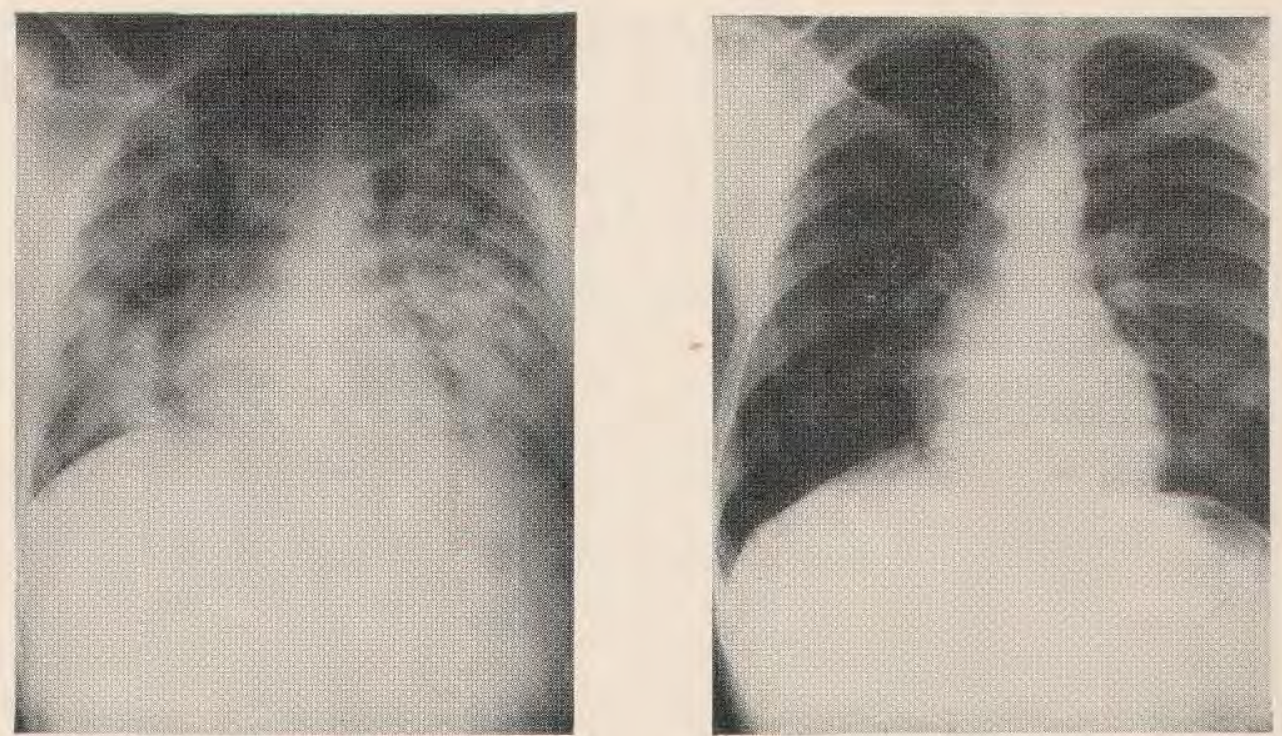

Fig. 2. Chest radiographs. (L) Four hours after admission. (R) Showing complete recovery after 28 hours

\section{Prevention the primary objective}

There appears to be a general agreement that those who are probably most at risk are the climbers who ascend rapidly above the critical height of, say, 9,000 feet and remain at or above that altitude for more than one day. This aspect may in part account for the few evident reports of cases described from the European Alps. A partial explanation of the apparent variation in the critical altitude is the descrepancy between calculated and actual barometer pressure in different seasons (Folk 1966).

The normal diuresis associated with adaption to altitude, in combination with exercised-induced sweating and breathing the dry air on high mountains, all contribute a tendency towards dehydration. This is often aggravated by the difficulty of carrying or acquiring sufficient drinking water at altitude. Houston (1971) has stressed that the maintenance of renal efficiency during the initial acclimatisation of the ascent is dependent to a degree upon a sufficient fluid intake, and instances two to three quarts per day, indeed, on Everest, it was found that three to four litres per day were required to maintain a urine output of 1.5 litres per day, and particular attention was given to this on the successful 1953 expedition (Vaughn 1965).

Prophylactic chemotherapy is finding increasing use where the pressures of schedules in modern life are confronted with the need to safeguard health in those who seek high adventure. It has been shown that acetazolamide (Diamox) is an effective protective medication (Forward et al 1968) which confers significant reductions in the most prominent symptoms of acute mountain sickness. Gray and his co-workers (1971) confirmed the benefit of acetazolamide in the prevention of sickness at altitude and Houston elaborates the regime thus: Two or three Diamox tablets taken for two days before and for one or two days after rapid ascent to above 10,000 feet. The value is believed to lie in its action as a carbonic anhydrase inhibitor and not because of its effect as a mild diuretic. It was considered potentially harmful to prescribe Diamox for longer periods. These researches have also established that Lasix, whilst being an 
essential drug in the treatment of pulmonary oedema, actually exacerbates the onset if taken as a prophylactic.

Acute pulmonary oedema is one of a number of non-communicable disorders to which expedition personnel may be at risk because of activity, climate or terrain. All are largely preventable if due regard is paid to basic safety considerations.

\section{Acknowledgements}

I am indebted to Dr. (Mrsl) J. Haigh of Nanyuki for access to the clinical data reported in this paper and to Dr. Ponte of the Consolata Mission Hospital, Nyeri, who kindly supplied the chest radiographs.

Professor Charles S. Houston of the Department of Community Medicine, University of Vermont, has given considerable assistance in reviewing the literature and I am also grateful to him for guidance upon certain points in the text of this paper.

BAtes, T. (1973). Brit. med. J. iii, 829.

\section{REFERENCES}

BRIT. MED. J. (1973). Leading Article. 26 May.

Corretelli, Prof. and Margaria, Prof. (1972). Discussion. Symposium on Pulmonary Oedema. Nyeri Kenya. 5 January.

Durig, A. and Zuntz, N. (1904) Arch. Anat. Physiol. P. 417.

FoLK, G. E. (1966). In 'Introduction to Environmental Physiology' Henry Kimpton. London. P. 212. Forward, S. A., Lansdowne, M., Follansbee, J. N. and Hansen, J. E. (1968). New Engl, J. Med. $279,1$.

Gray, G. W., Bryan, A. C., Frayser, R., Housion, C. S. and Rennie, 1. D. B. (1971). Aerospace Med. 42,81 .

Houston, C. S. (1960). New Engl. J. Med. 263, 478.

Houston, C. S. (1973). Summit (A Mountaineering Magazine). March.

Houston, C. S. (1972). Personnal communication.

Houston, C. S. (1971). New Engl. J. Med. 285, 1318.

Horrobin, D. (1972). Discussion. Symposium on Pulmonary Oedema. Kenya.

Hultgren, H. N., Spickard, W. B., Hellsiegal, K. and Houston, C. S. (1961). Medicine 40, 289.

Milne, J. H. (1973). Personnal communication. Def. Stats. 23 (a).

Mitchel., J. (1971). Guide Book to Mount Kenya. Kenya. P. 44.

Monge, C. (1928). La enfermedad de los Andes, Limda.

Mosso, A. (1898). Life of Man in the High Alps.

NoycE, W. (1962). They Survived. Heinemann Books. London.

Robin, E. D. et al (1973). New Engl. I. Med. 240, 239.

Singh, I. J., Kapila, C. C., Khanna, P. K., Nanda, R. B., and Rao, B. D. P. (1965). Lancet i, No. 7379,30 January.

Singh, 1, J., Khanna, P. K., Scrivastava, M. C., Lal, M., Roy, S. B. and Subramanyam, C. S. U. (1969). New Engl. J. Med. 280, 175.

SNyder, R. (1973). Personnal communication. Warden in Charge, Mount Kenya National Park.

STEELE, P. (1971). Lancet, 3 July.

VAughn, L. (1965). Proceedings 5th Symposium Arctic Medicine and Biology. Arctic Aero-Medical Laboratory. Fort Wainwright. Alaska.

West, J. B. (1970), In 'Ventilation/Blood Flow and Gas Exchange,' 2nd ed. F. A. Davis, Philadelphia.

Woodery, F. W. (1972). Warden, Mountain National Parks, Kenya. Discussion. Symposium on Pulmonary Oedema. Nyeri. Kenya.

Woodley, F. W. (1973). Personnal communication.

Zflis, R. F., Mason, D. T., Spann, J. F. and Amsterdam, E. A. (1970). Amer. J. Cardiol. $25,136$. 